\title{
Anotações sobre o universal e a diversidade*
}

\section{Renato Ortiz}

Universidade Estadual de Campinas, Instituto de Filosofia e Ciências Humanas
O termo universal é polissêmico, o uso que dele fazemos remete a diferentes tradições de pensamento. Uma primeira acepção vincula-se à herança do Iluminismo. Universal define uma qualidade da "natureza humana”. Os pensadores dos séculos XVII e XVIII divergiam na sua avaliação a respeito da sociedade, da passagem do estado selvagem para a vida coletiva, das formas de governo dos povos (democracia, despotismo, monarquia), da hierarquia das raças e da origem da linguagem. No entanto, eles partiam de um mesmo princípio: o homem. Esse é um ser objetivamente dado, raiz de toda sociedade, independentemente da forma como ela se autogoverna ou se estrutura. Ser racional, capaz de sair do estado da natureza por meio de um contrato social no qual o bem comum seria superior à vontade individual desregrada. O humanismo das $\mathrm{Lu}-$ zes funda-se nessa categoria transcendente e abstrata, ela permite as generalizações filosóficas sobre um conjunto diverso (historicamente) e homogêneo (filosofi-

* Conferência de abertura da 29a Reunião Anual da ANPEd, realizada em Caxambu, MG, de 16 a 20 de outubro de 2006. camente), passível de ser compreendido e ordenado segundo a razão: a humanidade.

Foucault (2002) acredita que esse seria um dos pilares da epistéme moderna que se consolida no final do século XVIII. Existiria assim uma história universal; ela é teleológica para Hegel, um aperfeiçoamento contínuo para Condorcet; malgrado as diferentes abordagens, permanece um núcleo inalterado, o substrato de toda e qualquer universalidade. Este é o sentido do texto de Kant (1991): O que é o Iluminismo? Sua resposta à pergunta é clara: é a saída do homem para fora do estado de tutela pelo qual ele mesmo é responsável. Postula-se portanto a existência de um homem guiado pela razão (ele é capaz de sair do estado de tutela) e um conjunto de valores pelos quais ele age no mundo: espírito de liberdade, uso público da razão, responsabilidade. "Natureza humana" associa-se, assim, a metavalores cuja realização seria evidentemente necessária. Quando Habermas escreve que "a modernidade é um projeto inacabado", ele pressupõe a manifestação desses valores universais; eles seriam transcendentais e anteriores à sua efetivação histórica, e em princípio fun- 
dariam e legitimariam a existência das sociedades modernas. A mesma premissa encontra-se em autores como Karl Apel, que considera imprescindível a existência de uma ética universal no contexto da globalização. Somente ela, o solo partilhado por todos os habitantes do planeta, seria capaz de estabelecer o diálogo permanente entre os indivíduos e as civilizações em conflito. Há vários inconvenientes em relação a esse tipo de abordagem. Prudentemente, ela evita tocar nos pontos problemáticos que a desmerecem: colonialismo, imperialismo, eurocentrismo, enfim, as relações de poder. Tudo se passa como se a expansão dos povos ocidentais coincidisse com a difusão das Luzes. E, como sublinha Bourdieu (1997), ela se esquece ainda de que esse universal é histórico, surge em determinado momento da vida de algumas sociedades européias, e que na disputa pelo seu "monopólio interpretativo" existem os interesses particulares daqueles que verdadeiramente o enunciam.

Um outro sentido do termo exprime-se no contraste que se faz entre sociedade e natureza, homem e mundo animal. Um exemplo, a distinção estabelecida pelos lingüistas entre língua e linguagem. Esta última seria uma faculdade universal, ou seja, uma capacidade inerente ao homo sapiens. Discute-se se sua aquisição seria um fenômeno que teria ocorrido por etapas ou abruptamente, mas há consenso em dizer que somente um determinado tipo de hominídeo a possui na sua plenitude (a elaboração do discurso). Por isso, todos os sapiens (para ser mais preciso, os sapiens sapiens) partilham uma mesma qualidade. $\mathrm{O}$ mesmo pode ser dito em relação à evolução do tamanho do crânio e do patrimônio genético. Os arqueólogos, paleontólogos e geneticistas buscam, assim, pelos traços universais dos seres humanos, e alguns chegam a dizer que o Paleolítico Superior (40.000 a.C. a 10.000 a.C.) inaugura a etapa da "modernidade" humana. A metáfora não é fortuita, pois o atributo da universalidade está intimamente associado à noção de modernidade.

Não há como negar a importância das descobertas arqueológicas e das pesquisas genéticas; de fato, elas permitem traçar um quadro plausível (sujeito à confirmação) da origem e da evolução dos hominídeos. No entanto, há algo de insatisfatório nisso tudo. No momento em que se determina um substrato comum a todos, um elemento específico os distancia: a cultura. A linguagem é uma faculdade universal dos seres vivendo em sociedade, mas as línguas, enquanto atualização da linguagem, os separa e os divide. Esse é o dilema de Babel, evento que alimentou em muitos pensadores a ilusão da existência de um idioma primevo, perfeito, anterior ao evento da confusão das línguas narrada na Bíblia. A diversidade das falas sobrepõe-se assim ao traço comum que lhes dá suporte. Contrastada ao reino animal, há realmente uma história do desenvolvimento dos hominídeos. Ela pode ser apreendida através de um conjunto de indícios, aumento da massa craniana, aprimoramento de algumas funções biológicas, surgimento dos utensílios, das vestimentas e dos funerais. O homo sapiens sapiens distingue-se dos outros homo, assim como das diversas formas de vida existentes no planeta. Entretanto, quando lemos sobre o Paleolítico Superior, às vezes nos esquecemos de imaginar que esses homens são também diferentes entre si, cultivam deuses e espíritos diversos, inserem-se em sociedades com estruturas de parentesco específicas, falam línguas e possuem tradições particulares. Um exemplo, preferido de Lévy-Strauss, pode ser apontado. $\mathrm{O}$ incesto existe em todas as sociedades humanas, ele seria universal. Não há por que negar tal afirmação, os estudos antropológicos a atestam, porém ela diz muito sobre o que as sociedades não são e pouco sobre como elas se organizam. O universal termina onde começam a cultura e a língua. Esse é o problema.

Na tradição sociológica, a noção investe-se de um outro significado. Para Durkheim não existe o homem, mas sim a sociedade. Sua compreensão contrapõe-se à perspectiva filosófica que postula a existência de uma essência a-histórica, a natureza humana. As sociedades são distintas entre si e sui generis, envolvem os indivíduos e os inserem numa rede de relações sociais. Nesse sentido, não existiria humanidade, unidade genérica na qual "todos" estariam incluídos. Isso fica claro no debate com Kant (1991) a respeito das cate- 
gorias de espaço e tempo. Para os filósofos, tais noções seriam abstratas e universais; Durkheim toma o caminho inverso, procura demonstrar que elas são sociais e dependem da organização das diferentes sociedades. Existiria, pois, uma sociologia das categorias de pensamento inteiramente distinta de sua suposta universalidade. Também Weber nos ajuda a compreender a problemática que nos interessa. Ele denomina de religiões universais um conjunto de crenças, tais como: judaísmo, confucionismo, budismo, bramanismo, cristianismo, islamismo, cuja apreensão do mundo propõe uma ética na qual o indivíduo escolheria, com maior ou menor grau de autoconsciência, o caminho de sua salvação. Weber contrapõe essas religiões às crenças mágicas, nas quais o elemento de escolha, de individuação, estaria contido pelas exigências das divindades locais e as práticas do costume.

Do ponto de vista sociológico, algumas dimensões dessa universalidade, além da questão da ética, merecem ser sublinhadas. Há, primeiro, a oposição ao particularismo, ou seja, aos costumes, valores e poderes restritos aos limites das localidades. As religiões universais, obras de intelectuais, repousam na escrita e têm uma maior capacidade de "universalização". A escrita é fundamental nesse processo. Contrariamente à oralidade, ela é um fator tecnológico que propicia a descontextualização das normas. O texto possibilita uma liberação dos limites provinciais, abrangendo um raio de maior amplitude. Ele favorece a expansão religiosa, via conversão, dando-lhe um alcance que supera em muito o localismo das crenças particulares (o mito). Outro aspecto diz respeito à capacidade de integração dos povos dentro de uma mesma norma de sentido. As religiões universais associam-se às civilizações, e muitas vezes constituemse num centro irradiador de sentido. Elas conseguem, dessa forma, integrar partes distintas dentro de um mesmo cosmo significativo. É o caso da China na Antigüidade. Uma de suas tradições filosóficas nasceu no século IV a.C., tendo sido codificada pelos discípulos de Confúcio ao longo dos anos. Mêncio (371-298) organiza os seus ensinamentos numa versão política coerente e orgânica, cujo objetivo seria fornecer às famílias aristocráticas (como o faz mais tarde Maquiavel) um código para governar. Entretanto, nessa época, o confucionismo era apenas uma entre diferentes escolas de pensamento. É somente com a unificação do Estado chinês (221 a.C.) que seu destino se modifica. Nesse momento, a fragmentação do poder imperial, manifestada nas disputas do feudalismo vigente, é superada por uma força política que encontra sua justificativa na teoria do "governo pela beneficência". O confucionismo, como doutrina de Estado, adquire agora a capacidade "universal" de integrar as partes do império chinês dentro de uma mesma totalidade simbólica.

A perspectiva sociológica permite-nos afirmar: existem vários universais que se contradizem uns aos outros e competem entre si (confucionismo versus budismo, budismo versus bramanismo, cristianismo versus islamismo etc). Eles não existem em abstrato, devem ser situados historicamente e qualificados em suas especificidades. O mesmo ocorre com o termo diferença: ele é também polissêmico.

A antropologia nos ensina que a noção de diversidade encontra-se intimamente associada à idéia do outro. Debruçando-se sobre as sociedades ditas primitivas, os antropólogos do século XIX queriam compreender um tipo de organização social radicalmente distinta do mundo que conheciam. Relações de parentesco, crenças mágicas e mitos encontravam-se a tal ponto distantes das concepções existentes que alguns autores, penso em Lévy-Bruhl, acreditavam ser impossível compreender a mentalidade pré-lógica desses povos.

As pesquisas antropológicas logo descobrem que as sociedades indígenas não apenas se contrapõem à modernidade, como cada uma delas constituía uma cultura específica, uma identidade própria. Guarani, nuer, hauça são elementos descontínuos, sociedades particulares diversas umas das outras. Por isso o debate sobre o relativismo cultural atravessa as discussões dos antropólogos desde o início de sua disciplina. Apesar da existência de correntes teóricas de cunho universalista, como o estruturalismo, a antropologia é marcada por uma perspectiva que valoriza a unida- 
de de cada cultura. Os povos dispersos no planeta constituem assim uma série diversificada na qual cada elemento possui características intrínsecas e irredutíveis. A história também tematiza a multiplicidade dos povos que se interpenetram e se sucedem ao longo do tempo: egípcios, sumérios, gregos, romanos, chineses, árabes, persas. Quadro que se transforma da Antigüidade à Idade Média. Muitas civilizações desaparecem, alimentando a crença de alguns historiadores de que as sociedades humanas seriam análogas aos organismos vivos. Toynbee e Spengler vulgarizaram a concepção de que cada civilização experimentaria um momento de ascensão e outro de declínio, de vida e de morte. Postuladas pela metáfora organicista, suas forças vitais extinguiriam-se com o tempo. Cada civilização possui um centro e um território geográfico; com seus costumes, língua, deuses, formas de governo (cidade-estado, império, monarquia), que constitui uma modalidade específica. Nesse sentido, diversidade significa diversidade de civilizações. Por fim, a sociologia mostra-nos que as sociedades modernas são marcadas pela diferenciação. Elas se contrapõem às sociedades tradicionais, nas quais predominaria o espírito comunitário. Nelas há uma maior divisão de trabalho, uma relação mais complexa entre as diferentes instâncias que arbitram a vida social. Durkheim trabalha essa complexidade por meio dos pares dicotômicos solidariedade mecânica e solidariedade orgânica; Tonnies, sociedade e comunidade.

O pólo tradicional tende a ser pensado como algo mais homogêneo, enquanto a modernidade é vista como um processo de diferenciação crescente, correndo, inclusive, o risco de transformar-se em anomia. Dentro dessa perspectiva, a cidade torna-se o lugar privilegiado das relações anônimas e impessoais, em contraposição aos agrupamentos rurais nos quais os contatos face-a-face favoreceriam os traços de coesão. Por isso Simmel a considera como o lugar no qual "explodem as diferenças" e se afirma a irredutibilidade do indivíduo. A modernidade carrega em seu bojo um forte elemento diferenciador.

Essa digressão leva-nos a uma conclusão análoga à anterior. A diferença não possui um valor “em si", uma "estrutura" ou "essência" atemporal. A diversidade existe em situações históricas determinadas, ela deve também ser qualificada. Nesse sentido, não é tanto a oposição em relação ao universal que interessa, mas como a mudança de contextos incide sobre a nossa compreensão desses conceitos.

Isso nos remete à problemática da globalização. Não tenho a intenção de trabalhá-la em suas diferentes dimensões (o fiz em outros escritos). Quero, no entanto, sublinhar um aspecto relevante para a discussão que nos concerne. Não creio na existência de uma "sociedade global", ou seja, em uma unidade sociológica homóloga às sociedade nacionais, na qual o processo de integração das partes se faria de maneira coerente e ordenada. Ou seja, uma metassociedade englobando todas as outras. $\mathrm{O}$ espaço transnacional não é da mesma natureza dos espaços nacionais. A metáfora "sociedade global" ilude-nos nesse sentido (por exemplo, muitos afirmam a existência de um espaço público transnacional como se ele fosse homólogo ao espaço público nacional). Tampouco acredito que as sociedades sejam sistêmicas. Afirmar a presença de um world system parece-me problemático. Prefiro dizer que o processo de globalização define uma nova situação. Uma situação é uma totalidade no interior da qual as partes que a constituem são permeadas por um elemento comum. No caso da globalização, essa dimensão penetra e articula as diversas partes dessa totalidade. Colocar a problemática nesses termos permite-nos evitar, primeiro, um falso problema, a oposição entre homogêneo e heterogêneo, levando-nos a pensar simultaneamente o comum e o diverso. A idéia de globalização sugere-nos muitas vezes a de unicidade.

Quando se fala de economia global tem-se em mente uma única estrutura marcando as trocas comerciais em todo o planeta. Os economistas podem inclusive medir a dinâmica dessa ordem globalizada utilizando um conjunto de indicadores: trocas e investimentos internacionais. $\mathrm{O}$ mesmo pode ser dito em relação à esfera tecnológica: ela é marcada pela unicidade das técnicas (computadores, satélites, energia nuclear etc.). Mas teria sentido pensarmos a di- 
mensão cultural da mesma maneira? Existiria "uma cultura global" ou "uma identidade global"? Certamente que não (Ortiz, 1994, 2006b). Por isso prefiro diferenciar entre os termos globalização e mundialização. O primeiro aplica-se bem à realidade técnica e econômica, o segundo adapta-se melhor ao universo da cultura. A categoria mundo articula-se assim a uma dupla dimensão. Ela vincula-se ao processo de globalização econômica e tecnológica; sem essa dimensão material dificilmente discutiríamos a mundialização da esfera cultural. Mas ela também corresponde à noção de "concepção de mundo", um universo simbólico específico, que se tece no interior do processo mas não se confunde inteiramente com ele. Concepção de mundo que se contrapõe a outras visões de mundo e que marca a diversidade dos elementos culturais na situação de globalização.

Há ainda um outro aspecto que deve ser ressaltado. Do ponto de vista conceitual, ao se operar com a idéia de situação, consigo evitar um tipo de dicotomia comum na discussão atual. Eu refiro-me aos pares de oposição: nacional/global, moderno/pós-moderno, tradição/modernidade, velho/novo, passado/ presente. Normalmente, cada um desses termos é visto como uma unidade antitética, como se entre eles existisse uma incongruência insuperável. Creio ser essa uma perspectiva equivocada, cuja lógica excludente percebe a história de forma linear. A crítica à noção de progresso (uma das premissas do universalismo do século XIX) já não é mais uma novidade, não há por que retornarmos à idéia da evolução unilinear do tempo, considerando o passado um anacronismo manifestado no presente. A situação de globalização caracteriza-se pela emergência do novo e pela redefinição do "velho". Ambos se encontram inseridos no mesmo contexto; nele, diversas temporalidades se entrecruzam. Não é, pois, necessário opor tradição a modernidade, local a global. Importa qualificar de que tipo de tradição estamos falando (a tradição da modernidade ou as tradições dos inúmeros grupos indígenas) e pensá-la nas formas de sua articulação à modernidade-mundo. Da mesma maneira, o local e o nacional não devem ser considerados como dimen- sões em vias de desaparecimento; trata-se de entender como esses níveis são redefinidos. Na situação de globalização co-existe, portanto, um conjunto diferenciado de unidades sociais: nações, regiões, tradições e civilizações. A diversidade é parte integrante dessa totalidade.

Esse é o contexto no qual se deve problematizar o universal e a diferença. Um primeiro aspecto merece ser sublinhado: uma mudança do humor dos tempos. Gostaria de marcar essa inflexão através de um exemplo: a busca de uma língua universal. Durante séculos, no mundo ocidental, essa aventura dominou a imaginação teórica de diversos autores, da Idade Média ao Iluminismo, da Revolução Francesa à construção dos idiomas artificiais. Acreditava-se primeiro na existência de um idioma falado no Paraíso, do qual todas as outras falas teriam se originado. Babel rompe esse equilíbrio, os homens já não mais se compreenderiam entre si e a paz anterior é substituída pela incompreensão generalizada. Como a confusão das línguas decorre da interferência divina, a passagem do uno ao diverso é vista como uma queda, levando à separação dos povos. Nos séculos XVI e XVII os pensadores abandonam a idéia do mito adâmico, mas estão convencidos da possibilidade de inventar uma língua universal, capaz de retratar a realidade tal como ela é, sem a distorção que as línguas vulgares infligiriam ao pensamento. Esse é o momento em que são construídos diferentes sistemas de linguagem dalgarno, wilkins, lodwick, leibniz. No XVIII, a idéia de língua filosófica inspira-se nos mesmos ideais; ela alimenta o debate entre os filósofos e se expressa na obra máxima da época, L’Encyclopédie. Ao longo do XIX emergem dezenas de propostas de línguas artificiais - volapuque (1879), esperanto (1887) e muitas outras, spokil, spelin, mundolíngua, neutral - e até meados do século XX o interesse pela existência de uma interlíngua manteve-se aceso por um certo militantismo lingüístico. Cito um exemplo eloqüente. Em 1795, ano III da República, o cidadão Jean Delorme (1975) apresenta à Convenção Nacional um projeto de língua universal. Ao justificar tal empreendimento, ele escreve: 
Neste momento de revolução, quando o espírito se regenera para os franceses, e se lança com tanta energia, não se poderia esperar para tornar pública uma nova língua que facilite as descobertas ao aproximar os sábios de diferentes nações, que seja mesmo um ponto comum a todas as línguas, fácil de ser dominado pelos homens menos suscetíveis à instrução, e que faça, com brevidade, de todos os povos uma grande família? ... as luzes aproximam e conciliam os homens de todas as maneiras. Essa língua, facilitando as comunicações, propagará as luzes. (p. 48-50)

A luz da razão aproxima os homens, os integra numa mesma comunidade e supera a ignorância entres eles e as nações. Apreender e divulgar essa nova língua é comungar os valores universais do Iluminismo.

O quadro lingüístico muda radicalmente no século XXI. O otimismo anterior cede lugar a um pessimismo agudo, e os valores universalistas do monolingüismo passam a ser vistos com desconfiança. $\mathrm{Na}$ década de 1990 surgem inúmeros trabalhos sobre os idiomas "em risco", "em perigo", "em sério perigo", "moribundos" ou "ameaçados". A crônica dessa morte anunciada espelha-se no Atlas de las lenguas del mundo en peligro de desaparición. Elaborado pela Unesco, ele nos revela a agonia lenta das falas dos pequenos grupos dispersos na face da Terra. Enfrentando situações profundamente adversas, diminuição drástica do número de falantes, perda de prestígio, necessidade de se adaptarem à convivência com as línguas mais fortes, elas lutam desesperadamente pela sobrevivência. A história bíblica condenava a multiplicidade das línguas, a redenção residia na espera messiânica e na depuração da decadência original. Ao hipertrofiar o uno, a diversidade inevitavelmente pendia para a imperfeição. A mudança do contexto tem agora novas implicações. No Atlas de las lenguas del mundo en peligro de desaparición, um dos argumentos centrais na luta contra esse estado das coisas enuncia-se assim:

Toda língua reflete uma cosmovisão e uma cultura únicas, e mostra como uma comunidade lingüística resolveu seus problemas de relação com o mundo e formulou seu pensamento, filosofia e sistema de conhecimento do universo que a rodeia. Cada idioma é o meio pelo qual se expressa o patrimônio cultural imaterial de um povo, e continua refletindo-o ainda durante algum tempo depois que o impacto com uma cultura diferente, intrusa, poderosa e geralmente metropolitana, provoca a decadência e destruição da cultura nele implícita. No entanto, com a morte e extinção de uma língua perde-se para sempre uma unidade insubstituível de nosso conhecimento da cosmovisão e do pensamento humanos. (Wurm, 1996, p. 1)

Há uma inversão das expectativas. O diverso é sinônimo de riqueza, patrimônio intocável. Cada idioma, na sua modalidade, é um universo irredutível aos outros, sua morte seria uma perda para o conjunto das visões de mundo dos diferentes povos. As noções de confusão e incompreensão, intrínsecas à polêmica anterior, são substituídas por outras, elas agora prezam o diverso e o plural. A idéia de unificação associa-se então à de pesadelo, ao declínio da vida humana. Ocorre assim uma ressemantização do mito de Babel. Suas qualidades nefastas transmutam-se em positividade. Pluralidade significa riqueza, e a proliferação dos idiomas é o sinal de sua manifestação. Em contrapartida, o unilingüismo associa-se à idéia de restrição; ele empobreceria a mente e as experiências culturais.

Uma maneira de se reagir a essa mudança de humor seria abraçar a idéia do "fim" do universal. Lyotard (1979), em seu clássico livro A condição pósmoderna, dizia que os grandes relatos tinham perdido toda credibilidade, sendo incapazes de legitimar as formas de interpretação do mundo. Restaria aos pequenos relatos a capacidade de ressignificá-lo. Haveria assim uma supremacia das diferenças diante das narrativas totalizadoras. Em parte Lyotard tem razão.

Alguns relatos certamente perdem força (por exemplo, aqueles tecidos pelos partidos políticos, que acreditavam ser capazes, a partir de uma ideologia específica, de construir uma ordem orgânica e totalizadora). Entretanto, alguns não significa todos. Pelo contrário, é possível reconhecer, no contexto da globalização, no qual as certezas pós-modernas são diri- 
midas, a emergência de novos relatos totalizadores e a reatualização de antigos relatos. Esse é o caso das religiões universais. Ao definirem-se como algo para "além das fronteiras" elas dispõem de um potencial de ação "universalizador", ou seja, mundial. Na medida em que têm capacidade de agregar pessoas em escala ampliada, elas criam laços sociais e memória coletiva. Enquanto linguagem, ideologia, concepções de mundo dispersas mas extensivas a grandes áreas territoriais, elas vinculam os interesses e coordenam as ações coletivas.

Uma política religiosa, dispondo agora de meios de comunicação mais eficazes (canais de televisão, cassetes, correio eletrônico, vídeos) pode então se concretizar (do interesse papal ao fundamentalismo islâmico). Sabemos que toda identidade é uma construção simbólica que se faz em relação a um referente, e há certamente uma multiplicidade deles: étnicos, nacionais, de gênero etc. Os relatos universais, para construírem suas centralidades, necessitam de um referente mundial. Por exemplo, o discurso ecológico. Ele constrói-se a partir do referente Terra comum a todos. Podese assim articular uma forma de compreensão dos problemas e dela, inclusive, retirar uma ética de ação no mundo: a defesa do planeta. Na situação de globalização, os relatos de vocação "universalista" são reativados, inclusive os elementos de "resistência", como o movimento alter-globalista, cujo intuito seria encontrar os caminhos para uma "outra globalização".

Creio ser possível dizer que muitos desses relatos competem e colidem entre si. Esse é o caso da oposição entre religião e consumo. É comum percebermos o consumo como algo exclusivo ao reino material, mera apropriação dos bens escolhidos segundo o gosto e as inclinações de cada um. Na verdade, ele pressupõe uma ética, uma disposição alimentada pelo imaginário coletivo. A publicidade não é apenas uma técnica de venda, ela é também fonte permanente de exemplaridade, de estilos de vida. Como as religiões, o consumo é uma floresta de símbolos, um universo repleto de signos, mitos, um mundo com particularidades e exigências próprias. Universo de abrangência planetária, devido aos meios de comuni- cação, às indústrias culturais, às corporações transnacionais, aos ídolos da música pop, às estrelas de cinema, constituindo uma verdadeira cultura mundializada. Como dizia Baudrillard (1970), ele é uma moral, requer uma forma de conduta - e, eu acrescentaria -, contrapondo-se a outras moralidades de envergadura mundial. Daí o antagonismo, por exemplo, entre islamismo e consumismo. Alguns autores captam muito bem esse movimento ao contrapor o shopping à mesquita. $\mathrm{O}$ shopping seduz, estimula os sentidos, imerge o indivíduo no reino das coisas, oferecendo-lhe a sensualidade das oportunidades; em contraste, a mesquita anula sua corporeidade, retira-o do fluxo cotidiano, sua arquitetura imponente impressiona, o transcende, revelando sua condição finita diante da imensidão de Deus. No shopping prevalece o hedonismo, a realização imediata dos desejos - I want and I want it now é o seu lema -; na mesquita eles estão suspensos, asceticamente contidos pela emanação divina. Ela é o lugar de oração, de predicação, na qual o fiel atentamente escuta os sermões que lhe ensinam a luta eterna entre o bem e o mal, o Islão e o Ocidente. O mundo feérico dos objetos é um anátema, tentação a ser evitada. O consumo oferece uma promessa de vida que contradiz e compete diretamente com a conduta rígida e ascética religiosa. A literatura produzida pelos teólogos católicos e protestantes é repleta de exemplos análogos. Ela nos explica que a instituição mercado existe de longa data na história das sociedades, e nada há de errado nisso. Porém, no passado sua existência teria sido guiada por outras forças, a tradição moral, as restrições legais, e sobretudo as concepções religiosas. O mercado global é o contrário disso tudo, funcionaria sem nenhum freio, uma espécie de Prometeu desacorrentado. Cox (1999) escreve:

[...] como teólogo cristão sugiro que a religião do mercado, que é a substância do mercado global, de uma perspectiva cristã é claramente uma idolatria, uma falsa religião, mas que ao invés de combatê-la, como fizeram os cristãos em Éfeso, eles hoje freqüentemente são coniventes com ela, e algumas vezes até mesmo a sacralizam. (p. 388) 
Religião e mercado surgem assim como entidades morais concorrentes entre si. Cada uma com seus deuses, suas exigências, sua ética própria.

A historicidade das diferenças exige também que elas devam ser qualificadas. Um primeiro aspecto diz respeito à sua não-equivalência. Dito de outra maneira, elas são diferentes entre si. Na situação de globalização encontramos tribos indígenas, civilizações, países, nações, classes sociais etc. Os grupos indígenas nada têm de semelhantes, eles congregam povos nômades, como no interior da Amazônia, e segmentos populacionais majoritários em países como Bolívia, Peru e Paraguai. Alguns lutam pela defesa da terra, e para preservar seu modo de vida desejam se afastar das formas modernas de organização social. Outros reivindicam uma maior participação na vida pública, votam, elegem presidentes da república, são parte ativa do espaço político. A diversidade das nações é também patente, dos países que conheceram a Revolução Industrial ainda no século XIX aos africanos, cuja emancipação ocorre somente em meados do século XX. Cada nação possui uma história própria, seus conflitos e mitos. A diversidade manifesta-se também na esfera do mercado. Os produtos são orientados para grupos específicos de consumidores, eles penetram em determinados nichos, não em outros. Longe de ser homogêneo, como pensavam os teóricos da comunicação de massa, o mercado é atravessado por uma miríade de diferenças, basta olharmos a diversidade dos estilos de vida. Entretanto, não devemos pensar a diferença como um Ser, uma essência; ela é sempre relacional e encontra-se situada num contexto determinado. Toda diferença é produzida socialmente e é portadora de sentido histórico. O relativismo é uma visão que pressupõe a abstração das culturas de suas condições reais; tem-se a ilusão de que cada uma delas seria inteiramente autocentrada. Esse estatuto, postulado pelo raciocínio metodológico é negado pela história. As sociedades são relacionais, mas não relativas. Suas fronteiras entrelaçam-se e muitas vezes ameaçam o território vizinho. $\mathrm{O}$ debate sobre a diversidade não se restringe, pois, ao argumento lógico-filosófico; ele necessita ser contextualizado.
Dizer que a diferença é produzida socialmente nos permite distingui-la da idéia de pluralismo. Traduzir o panorama sociológico em termos políticos é enganoso, pois pressupõe que cada uma dessas múltiplas unidades possui a mesma validade social. Nessa perspectiva, a questão do poder se esvai. Desenvolveu-se recentemente um tipo de literatura que gira em torno da passagem do homogêneo para o heterogêneo. Ela está presente sobretudo nos escritos dos executivos das transnacionais e de certos economistas. A história é apreendida em termos dicotômicos, como se estivéssemos no umbral de uma nova era, uma "terceira onda". Para essa perspectiva, o passado teria sido unívoco, privilegiando os "grandes relatos"; em contrapartida, o presente se caracterizaria pela disseminação das diferenças e da multiplicidade identitária. Aplicada ao mercado, tal visão otimista das coisas assimila o homogêneo ao fordismo, à produção em massa, e o heterogêneo ao diverso, à flexibilidade. O mundo atual seria múltiplo e plural. Diferenciação e pluralismo tornam-se assim termos intercambiáveis e, o que é mais grave, ambos se fundem no conceito de democracia.

Há nessa operação lógica algo de ideológico. Ela se esquece de dizer que o pluralismo hierarquizado organiza as diferenças segundo uma relação de forças. Como corolário deste argumento, pode-se dizer que as diferenças também escondem relações de poder. Assim, o racismo afirma a especificidade das raças, para, em seguida, ordená-las segundo uma escala de valor. Por isso é importante compreender os momentos em que o discurso sobre a diversidade oculta questões como a desigualdade. Sobretudo quando nos movemos no interior de um universo no qual a assimetria entre países, classes sociais e etnias é insofismável. É insatisfatória a imagem de que o mundo seria multicultural, formado por um conjunto de "vozes". Ele dificilmente poderia ser visto como um caleidoscópio, metáfora freqüentemente utilizada por vários autores, instrumento que combina os fragmentos coloridos de maneira arbitrária em função do deslocamento do olho do observador. As interações entre as diversidades não são arbitrárias. Elas 
se organizam de acordo com as relações de força manifestas nas situações históricas concretas (países fortes versus países fracos; transnacionais versus governos nacionais; civilização "ocidental” versus mundo islâmico; estado nacional versus grupos indígenas).

Universal e particular são pares opostos. A diferença associa-se ao pólo do particular, e nesse sentido seria incompatível com o movimento de universalização. Universal remete-nos à idéia de expansão, quebra de fronteiras, "todos", humanidade; diferença associa-se a particular, contenção, limites, identidade. Entretanto, na situação de globalização, muitas vezes esse par antagônico se entrelaça, mesclando alguns valores antes fixados a apenas um de seus elementos. A afirmação "a diversidade dos povos deve ser preservada", utilizada em diversos documentos de organismos nacionais e internacionais, nada tem de natural. Pelo contrário, deveríamos nos surpreender diante de sua estranheza, pois ela carrega consigo uma carga de sentido inteiramente nova. Dizer que as culturas são um "patrimônio da humanidade" significa considerar a diversidade enquanto valor universal. Todos devemos cultivá-la e respeitá-la. A crítica ao etnocentrismo, assimilada na maioria das vezes à dominação ocidental, somente pode ser validada quando se manifesta como algo que transcende a província de cada cultura, de cada identidade. É isso que nos permite dizer: "as culturas minoritárias correm o risco de desaparecer, necessitamos preservá-las”; "as culturas precisam ser consideradas nos contextos aos quais elas pertencem"; "precisamos valorizar todas as facetas da memória coletiva da humanidade"; "o respeito a todas as culturas é um direito de reconhecimento à diferença". Há nessa operação semântica uma redefinição do que seria impensável nos marcos anteriores: o diverso torna-se um bem comum. A discussão sobre o espaço público transnacional (que existe apenas como um ideal), a rigor, pode ser travada unicamente nesses termos (por isso insistimos em falar de "sociedade civil mundial" ou de "cidadania mundial"). Ao tomar o planeta como unidade de ação, apenas uma perspectiva "cosmopolita" (para não uti- lizar o termo universal) faz sentido (caso contrário, nos encerraríamos nos limites de cada diferença). Não deixa de ser paradoxal (ou talvez irônico) perceber que a valorização de uma política de reconhecimento do outro encontra em Hegel (particularmente na dialética do senhor e do escravo), um ferrenho universalista, os elementos para sua afirmação.

Na verdade, mesmo na discussão sobre políticas concretas em relação às "minorias" nos deparamos com esse aparente paradoxo. Esse é o caso das chamadas políticas afirmativas (não é minha intenção defendê-las ou criticá-las nesse momento). Podemos considerá-las no seu contraponto com as ações mais universalistas, republicanas, em princípio dirigidas a todos. Não obstante, não se pode esquecer que a valorização das diferenças se faz em nome de um ideal também universalista: democracia, igualdade, cidadania. Por exemplo, os negros criticam as barreiras existentes na sociedade porque elas não lhes permitem ter o mesmo tratamento que os brancos; a reivindicação identitária repousa, portanto, na denúncia da desigualdade. Ora, esse tipo de julgamento pressupõe uma herança da modernidade, que, longe de se extinguir, legitima o discurso e a ação.

Humanidade, democracia, cidadania, igualdade tornam-se assim valores mundiais, sendo reivindicados na sua amplitude, inclusive para ressignificar as diferenças. Eles certamente já não mais possuem o mesmo significado que lhes atribuía o ideal iluminista. Tampouco as condições para sua realização (diria Habermas) se ajustam às expectativas anteriores (sepultadas pelo etnocentrismo, as guerras, o capitalismo flexível). Entretanto, sua expressão, ao redefinir-se na situação de globalização, mantém-se e transforma-se, tendo agora diante de si o planeta como cenário de sua materialização.

\section{Referências bibliográficas}

BAUDRILLARD, Jean. La société de consommation. Paris: Denoel, 1970.

BOURDIEU, Pierre. Méditations pascaliennes. Paris: Seuil, 1997. COX, Harvey. Pentecostalism and global market culture. In: 
EMPSTER, M.W. alli (org.). The globalization of Pentecostalism. Irvine, California: Regnun Books International, 1999.

DELORMEL, Jean. Projet d'une langue universelle, presenté à la Convention Nationale. Paris: l'Auteur, 1795.

FOUCAULT, Michel. As palavras e as coisas. São Paulo: Martins Fontes, 2002.

KANT, Emmanuel. Qu'est-ce que les lumières. Paris: Flammarion, 1991

LYOTARD, François. La condition postmoderne. Paris: Minuit, 1979.

ORTIZ, Renato. Mundialização e cultura. São Paulo: Brasiliense, 1994.

Mundialização: saberes e crenças. São Paulo:

Brasiliense, 2006a.

Mundialization/globalization. Theory Culture and

Society, v. 23, n. 2-3, p.401-403, march-may, 2006b.
WURM, Stephen. Atlas de las lenguas del mundo en peligro de desaparición. Paris: UNESCO, 1996.

RENATO ORTIZ, graduado pela Université de Paris VIII, mestre e doutor pela École des Hautes Études en Sciences Sociales (1975), com pós-doutorado pela Columbia University, École des Hautes Études en Sciences Sociales, University of Oxford e pela The City University of New York, é professor do Instituto de Filosofia e Ciências Humanas da Universidade Estadual de Campinas: Publicações recentes: Mundialização: saberes e crenças (São Paulo: Brasiliense, 2006); Ciências sociais e trabalho intelectual (São Paulo: Olho d’Água, 2004).E-mail: rortiz@terra.com.br

Recebido em outubro de 2006 Aprovado em dezembro de 2006 


\section{Resumos/Abstracts/Resumens}

\section{Renato Ortiz}

\section{Anotações sobre o universal e a diversidade}

$\mathrm{O}$ artigo tem por objetivo problematizar o universal e a diversidade. Investiga as possíveis implicações da polissemia dos termos universalidade $\mathrm{e}$ diferença, dentro das perspectivas filosófica, sociológica e antropológica. Destaca que a diferença não possui um valor “em si”, uma "estrutura” ou “essência” atemporal. A diversidade existe em situações históricas determinadas, ela deve também ser qualificada. Nesse sentido, não é tanto a oposição em relação ao universal que interessa, mas a forma como a mudança de contextos incide sobre nossa compreensão desses conceitos. Discute ainda a questão do local e do nacional, que não são considerados dimensões em via de desaparecimento dentro da "sociedade global". Busca, então, entender como esses níveis são redefinidos, visto que na globalização co-existe um conjunto diferenciado de unidades sociais: nações, regiões, tradições, civilizações e a diversidade é parte integrante dessa totalidade. Conclui que universal e particular são pares opostos. A diferença associa-se ao particular, à contenção, aos limites e à identidade, sendo assim incompatível com o movimento de universalização. $\mathrm{O}$ universal remete à idéia de expansão, quebra de fronteiras, “todos”, humanidade. Entretanto, na situação de globalização, muitas vezes esse par antagônico se entrelaça, mesclando alguns valores antes fixados a apenas um de seus elementos.

Palavras-chave: universal e diversidade; universalidade e diferença

Notes on the universal and diversity The aim of this article is to problematise the universal and diversity. It investigates the possible implications of the multiple meanings of the terms universality and difference, within the philosophic, sociological and anthropological perspectives. It points out that difference does not possess a value "in itself", nor a "structure" nor a timeless "essence". Diversity exists in determined historical situations and also needs to be qualified. In this sense, it is not so much the opposition in relation to the universal which interests us but the way in which a change of contexts affects our understanding of those concepts. It also discusses the question of the local and the national which are not considered as dimensions of "global society" on the point of disappearing. It then seeks to understand how these levels are redefined, given that in globalization a differentiated set of social unities exists: nations, regions, traditions, civilizations and diversity is an integral part of this totality. It concludes that universal and particular are opposing pairs. Difference is associated with the particular, with contention, with limits and with identity and is thus incompatible with the movement of universalisation. The universal refers to the idea of expansion, the breaking of frontiers, "everyone", humanity. However, within the context of globalization this antagonistic pair is 
frequently intertwined, mixing some

formerly fixed values with just one of its elements.

Key words: universal and diversity; universality and difference

\section{Anotaciones sobre lo universal y la diverdidad}

El artículo tiene por objetivo problematizar lo universal y la diversidad. Investiga las posibles inplicaciones de la polisemia de los téminos universalidad y diferencia, dentro de las perspectivas filosófica, sociológica y antropológica. Destaca que la diferencia no posee un valor "en sí”, una "estructura” o "esencia" atemporal. La diversidad existe en situaciones históricas determinadas, ella debe también ser calificada. En este sentido, no es tanto la oposición en relación a lo universal que interesa, mas la forma como el cambio de contextos incide sobre nuestra comprensión de esos conceptos. Discute incluso la cuestión de lo local y de lo nacional, que no son considerados como dimensiones en vía de desaparecimiento dentro de la "sociedad global". Busca, entonces, entender como esos niveles son redefinidos, ya que en la globalización co-existe un conjunto diferenciado de unidades sociales: naciones, regiones, tradiciones, civilizaciones y la diversidad es parte integrante de esa totalidad. Concluye que universal y particular son pares opuestos. La diferencia se asocia a lo particular, a la contención, a los límites y a la identidad, siendo así incompatible con el movimiento de universalización. Lo universal nos remite a la idea de expansión, quiebra de fronteras, "todos", humanidad. Entre tanto, en la situación de globalización, muchas veces ese par antagónico se entrelaza, mezclando algunos valores antes fijados solamente a uno de sus elementos.

Palabras claves: universal y diversidad; universlidad y diferencia 